\title{
Chikungunya Outbreak in the Republic of the Congo, 2019-Epidemiological, Virological and Entomological Findings of a South-North Multidisciplinary Taskforce Investigation
}

\author{
Francesco Vairo ${ }^{1,+}$, Martin Parfait Aimè Coussoud-Mavoungou ${ }^{2,+}$, Francine Ntoumi ${ }^{3,4,5, *,+}$, \\ Concetta Castilletti ${ }^{1}$ (D) , Lambert Kitembo ${ }^{6}$, Najmul Haider ${ }^{7} \mathbb{D}$, Fabrizio Carletti ${ }^{1}$ (D), \\ Francesca Colavita ${ }^{1}\left(\mathbb{D}\right.$, Cesare E. M. Gruber $^{1}{ }^{\mathbb{D}}$, Marco Iannetta $^{1}$, Francesco Messina ${ }^{1}(\mathbb{D}$, \\ Simone Lanini ${ }^{1}$, Biez Ulrich Judicaë1 ${ }^{6}$, Emanuela Giombini ${ }^{1}$ (D), Chiara Montaldo ${ }^{1}$ (D), \\ Chantal Portella ${ }^{8}$, Steve Diafouka-Diatela ${ }^{5}$, Martina Rueca ${ }^{1}(D)$, Richard Kock ${ }^{7}$ (D),

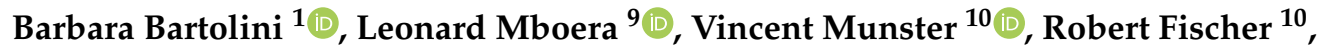 \\ Stephanie Seifert ${ }^{10}$, César Muñoz-Fontela ${ }^{11,12}$ (D), Beatriz Escudero-Pérez ${ }^{11}$, \\ Sergio Gomez-Medina ${ }^{11}$, Emily V. Nelson ${ }^{11}$, Patrick Kjia Tungu ${ }^{13}$, Emanuele Nicastri ${ }^{1}$, \\ Vincenzo Puro ${ }^{1}$ (D), Antonino Di Caro ${ }^{1}\left(\mathbb{D}\right.$, Maria Rosaria Capobianchi ${ }^{1}$, \\ Jacqueline Lydia Mikolo ${ }^{6,14,+}$, Alimuddin Zumla $15,16,+(\mathbb{D}$, Giuseppe Ippolito $1, *,+(\mathbb{D})$ and \\ on behalf of the Pandora-ID-NET Consortium Chikungunya Outbreak Group Taskforce $\ddagger$
}

1 National Institute for Infectious Diseases 'Lazzaro Spallanzani', IRCCS, 00149 Rome, Italy; francesco.vairo@inmi.it (F.V.); concetta.castilletti@inmi.it (C.C.); fabrizio.carletti@inmi.it (F.C.); francesca.colavita@inmi.it (F.C.); cesare.gruber@inmi.it (C.E.M.G.); Marco.Iannetta@inmi.it (M.I.); francesco.messina@inmi.it (F.M.); simone.lanini@inmi.it (S.L.); emanuela.giombini@inmi.it (E.G.); chiara.montaldo@inmi.it (C.M.); martina.rueca@inmi.it (M.R.); barbara.bartolini@inmi.it (B.B.); emanuele.nicastri@inmi.it (E.N.); vincenzo.puro@inmi.it (V.P.); antonino.dicaro@inmi.it (A.D.C.); maria.capobianchi@inmi.it (M.R.C.)

2 Fondation Congolaise Pour la Recherche Médicale (FCRM), Brazzaville CG-BZV, Congo; dl.congo@unesco-delegations.org

3 Ministry of Science and Technology, Brazzaville CG-BZV, Congo

4 University Marien Ngouabi, Brazzaville CG-BZV, Congo

5 Institute for Tropical Medicine, University of Tübingen, 72074 Tübingen, Germany; diafkietelas@fcrm-congo.com

6 Ministry of Public Health, Brazzaville CG-BZV, Congo; litchea@cg.afro.who.int (L.K.); sante@gouv.cd (B.U.J.); jlmikolo@gmail.com (J.L.M.)

7 The Royal Veterinary College, University of London, Hawkshead Lane, Hertfordshire NW1 0TU, UK; nhaider@rvc.ac.uk (N.H.); rkock@rvc.ac.uk (R.K.)

8 Department de Sante Publique, Pointe Noire CG-16, Congo; port22chant@gmail.com

9 SACIDS Foundation for One Health, Sokoine University of Agriculture, Morogoro 30007, Tanzania; leonard.mboera@sacids.org

10 Virus Ecology Unit, Laboratory of Virology, Rocky Mountain Laboratories, NIAID/NIH, Bethesda, MD 20814, USA; vincent.munster@nih.gov (V.M.); robert.fischer@nih.gov (R.F.); stephanie.seifert@nih.gov (S.S.)

11 Bernhard Nocht Institute for Tropical Medicine, Bernhard Nocht Strasse, D-20359 Hamburg, Germany; munoz-fontela@bnitm.de (C.M.-F.); escudero.perez@bnitm.de (B.E.-P.); gomez-medina@bnitm.de (S.G.-M.); nelson-emily@bnitm.de (E.V.N.)

12 German Center for Infection Research (DZIF), Partner Site Hamburg, 38124 Hamburg, Germany

13 National Institute for Medical Research, Dar es Salaam 9653, Tanzania; hq@nimr.or.tz

14 Laboratoire National de la Santè Publique, Brazzaville CG-BZV, Congo

15 Division of Infection and Immunity, Center for Clinical Microbiology, University College London, London WC1E 6BT, UK; a.zumla@ucl.ac.uk

16 National Institute of Health Research Biomedical Research Centre at UCL Hospitals, London W1T 7HA, UK

* Correspondence: fntoumi@fcrm-congo.com (F.N.); giuseppe.ippolito@inmi.it (G.I.)

+ These authors contributed equally to this work. 
$\ddagger \quad$ Membership of the Pandora-ID-NET Consortium Chikungunya Outbreak Group Taskforce is provided in the Acknowledgments.

Received: 13 August 2020; Accepted: 10 September 2020; Published: 13 September 2020

Abstract: The Republic of Congo (RoC) declared a chikungunya (CHIK) outbreak on 9 February 2019. We conducted a ONE-Human-Animal HEALTH epidemiological, virological and entomological investigation. Methods: We collected national surveillance and epidemiological data. CHIK diagnosis was based on RT-PCR and CHIKV-specific antibodies. Full CHIKV genome sequences were obtained by Sanger and MinION approaches and Bayesian tree phylogenetic analysis was performed. Mosquito larvae and 215 adult mosquitoes were collected in different villages of Kouilou and Pointe-Noire districts and estimates of Aedes (Ae.) mosquitos' CHIKV-infectious bites obtained. We found two new CHIKV sequences of the East/Central/South African (ECSA) lineage, clustering with the recent enzootic sub-clade 2, showing the A226V mutation. The RoC 2019 CHIKV strain has two novel mutations, E2-T126M and E2-H351N. Phylogenetic suggests a common origin from 2016 Angola strain, from which it diverged around 1989 (95\% HPD 1985-1994). The infectious bite pattern was similar for 2017, 2018 and early 2019. One Ae. albopictus pool was RT-PCR positive. The 2019 RoC CHIKV strain seems to be recently introduced or be endemic in sylvatic cycle. Distinct from the contemporary Indian CHIKV isolates and in contrast to the original Central-African strains (transmitted by Ae. aegypti), it carries the A226V mutation, indicating an independent adaptive mutation in response to vector replacement (Ae. albopictus vs Ae. aegypti).

Keywords: chikungunya; Republic of Congo; outbreak; Aedes spp; mosquito; arbovirus; ONE-HEALTH

\section{Introduction}

Re-emerging zoonotic infectious diseases cause much human suffering worldwide, particularly in West and Central Africa where major arbovirosis and other zoonotic epidemics keep occurring. The recent Ebola virus disease (EVD) epidemics in West Africa (2013-2016) and in the Democratic Republic of Congo (DRC) (2018-2020) highlighted that, once an infectious disease takes hold locally, the region and the rest of the world is put at risk [1,2]. This stresses the need of an effective north-south cooperation and of a ONE-HEALTH approach including human, environmental and animal health sectors, to effectively address recurrent and emergent zoonotic threats.

Chikungunya (CHIK) is a disabling and debilitating zoonotic disease of humans caused by the chikungunya virus (CHIKV). CHIKV is an alphavirus showing four different genotypes originally based on geographical regions: the West African genotype (Senegal and Nigeria), the East/Central/South African (ECSA) genotype, the Asian genotype and the Indian Ocean Lineage (IOL) genotype [3-7]. CHIKV was first isolated in southern Tanzania in 1952 from the serum of a patient during an outbreak of an exanthematous febrile disease. Aedes (Ae.) aegypti was identified as the vector [8]. Since then, an unnoticed and retrospectively diagnosed large outbreak affected Cameroon in 2006 [9] and Gabon a year later, with a total of 20,000 suspected cases. Ae. albopictus was identified as the main vector [10]. CHIKV isolates from the 2007 Gabon outbreak belonged to the ECSA lineage with the E1-A226V mutation [10], which increases the competence of Ae. albopictus as disease vector [11,12]. In 2011, the same ECSA lineage caused an outbreak in the Republic of Congo (RoC) with 11,083 cases (91\% from Brazzaville and 9\% from the Pool Department) $[13,14]$. CHIKV has also spread beyond its original locations (Americas, Africa and Indian subcontinent) to the northern hemisphere including Europe [15]. In February 2019, RoC government declared an outbreak of CHIK in Kouilou, Pool, and Bouenza regions.

The aim of our investigation is a better understanding of the epidemiological dynamics of the 2019 CHIK outbreak in RoC, in order to support the local response, as requested to the recently established 
PANDORA-ID-NET consortium (https://www.pandora-id.net/), by The Congolese Foundation for Medical Research (FCRM) and by The National Public Health Laboratory (LNSP).

\section{Materials and Methods}

\subsection{Study Sites}

Health districts in the RoC, Kouilou, Pointe-Noire, Bouenza, Niari and Pool departments. The surveillance system was enhanced for active case finding and contacts' tracing. Data on patients' age, sex, place of living, time of symptoms' onset and clinical symptoms were collected, and a notification form was distributed to the health facilities for regular central notification of suspected and confirmed cases.

\subsection{Study Case Definitions}

Suspect CHIK case: Patient presenting with acute onset of fever and joint pain;

Case Under investigation: Any suspected CHIK case with an epidemiological link with an area of ongoing circulation without laboratory confirmation;

Confirmed CHIK case: Patient with positive CHIKV RT-PCR or/and positive indirect immune fluorescence assay (IFA) or/and positive rapid test;

Non CHIK case: individual with negative CHIKV-RT-PCR and IFA; negative Rapid test and IFA.

\subsection{Laboratory Diagnostics}

CHIKV viral genome and standard CHIKV antibody testing were performed. Viral RNA was extracted from serum using QIAamp Viral RNA Mini Kit (QIAGEN ${ }^{\circledR}$, Milan, Italy), for qualitative detection of CHIKV RNA with an "in-house" real-time RT-PCR. Specific CHIK IgG and IgM were detected using indirect immune fluorescence assay (IFA) (Anti-chikungunya Virus IIFT, Euroimmun AG, Luebeck, Germany). To overcome logistical shortcomings and to be able to operate in the field, a rapid test for specific IgG and IgM detection was used (STANDARD F chikungunya IgM/IgG FIA SDBIOSENSOR, Chungcheongbuk, Republic of Korea), with sensitivity $97 \%$ and specificity $99 \%$.

\subsection{Genomic Analyses}

Two near complete CHIKV genome sequences were obtained from serum samples of two acutely infected women, one living in Tchali, Pointe Noire, collected on the 20 of March (n. 1, 63 years old) and the other living in Nkoungou, Pointe Noire, collected on the 5 of March (n. 2, age not available). Symptoms started 3-4 days before sampling.

The virus sequence from patient $\mathrm{n}$. 1 was obtained by Sanger sequencing according to previously published procedures [16,17]. Specifically, a 11,434 nt long sequence was amplified in 24 overlapping RT-PCR amplicons (cycling condition: $50^{\circ} \mathrm{C} \times 30^{\prime} ; 94^{\circ} \mathrm{C} \times 15^{\prime} ; 94^{\circ} \mathrm{C} \times 40^{\prime \prime}-56^{\circ} \mathrm{C} \times 40^{\prime \prime}-72{ }^{\circ} \mathrm{C} \times 1^{\prime}(\times 40)$; $\left.72^{\circ} \mathrm{C} \times 10^{\prime}\right)$ and Sanger sequenced (CHIK/PNRCNG/LNSP_INMI1-2019, GenBank accession number MK935343). Primers used for RT-PCR and sequencing were designed based on the reference sequence of Pakistan-07/2016 CHIKV isolate complete genome (GenBank accession number: MF774617.1) and are listed in Table S1. The virus sequence from patient $\mathrm{n}$. 2 was obtained by next generation sequencing (NGS), with the handheld third generation Nanopore sequencing technology MinION (Oxford Nanopore Technologies, Oxford, UK), using the approach described for field investigation on Ebola virus [2]. In particular, multiple sequence specific RT-PCR reactions were performed, (cycling condition: $\left.45^{\circ} \mathrm{C} \times 20^{\prime} ; 94^{\circ} \mathrm{C} \times 5^{\prime} ; 94^{\circ} \mathrm{C} \times 20^{\prime \prime}-58^{\circ} \mathrm{C} \times 20^{\prime \prime}-68^{\circ} \mathrm{C} \times 2.5^{\prime}(\times 40) ; 68^{\circ} \mathrm{C} \times 10^{\prime}\right)$, generating five overlapping amplicons, assembled in a 11,787 nt long sequence (CHIK/PNRCNG/LNSP_INMI2-2019, GenBank accession number MK935344). MinION sequencing of pooled amplicons was performed according to manufacturer's instructions using the Ligation Sequencing kit (Nanopore SQK-LSK109) on a FLOMIN106 flowcell. Primers used for RT-PCR and sequencing are listed in Table S2. 


\subsection{MinION Sequencing Data Analysis}

The raw sequencing data were archived on a portable hard disk and analyzed offline. Correction and assembly were performed using Canu program [18]. The longest contig was compared to the non-redundant database using Blastn [19]. The nearest genome (LC259094) was used as reference to perform a consensus sequence through Burrows-Wheeler Aligner (BWA-MEM) [20]. The sequence obtained by BWA was aligned to the longest contig, and ambiguities were solved.

\subsection{Phylogenetic Analysis}

The phylogenetic trees were built using Maximum-Likelihood (ML) method and Bayesian Maximum Credibility tree to date back the coalescent events; besides the CHIK/PNRCNG/LNSP_INMI1-2019 and CHIK/PNRCNG/LNSP_INMI2-2019 sequences, both trees included 60 additional full-length genome retrieved from the NCBI database, representing the 3 major described CHIKV lineages: ECSA ( $n=44$, including the Indian Ocean sub-lineage, $n=26)$, Asia-Caribbean $(n=12)$, and West African $(n=4)$. Evolutionary distances for ML were computed using the General Time Reversible model (GTR) with Gamma distribution, and bootstraps were generated using 500 replicates, using the MEGA X software 10.1.

Bayesian phylogenetic tree was inferred using Bayesian Markov chain Monte Carlo (MCMC) approach available in BEAST v1.10.4 [21]. General time reversible model plus Gamma distributed rates among sites (GTR $+\mathrm{G})$ was used as nucleotide substitution model and independent MCMC runs were carried out for strict model, along with constant population size coalescent priors. Chains were conducted for at least $100 \times 106$ generations with sampling every 10,000 steps and burn-in $10 \times 106$ generations. The convergence of the MCMC was assessed by calculating for each parameter the ESS (accepted if ESS > 250). Maximum clade credibility tree was obtained from the trees' posterior distributions with the Tree-Annotator software v 1.10.4 [21].

\subsection{Mutational Analysis}

Mutational analysis for ORF 1 and ORF 2 proteins was performed using the prototype 1953 Tanzanian strain S27 (GenBank accession number: AF369024) as reference. Uniqueness of amino acid substitutions, first identified by comparison with the full genome sequences included in the phylogenetic tree, was verified by performing BLASTp search for 21 amino acid long peptides spanning the location of each substitution of interest, considering the first 100 hits from all (both full genome and partial) CHIKV sequences available in GenBank.

\subsection{Estimation of Infectious Bites of CHIKV by Aedes Mosquito}

We developed a biological process model and a mechanistic transmission model that follow the biological event of vectors and hosts independently as previously described for a different pathogen [22,23]. The model followed a cohort of mosquitos each day of a transmission season until they die and estimated the daily survival rate, the biting rate, and the Extrinsic Incubation Period with the mathematical equations provided earlier (Table 1). The model ran for one cohort of mosquitos at a time, starting with the cohort that bit on the first day of the selected period, and ran progressively through the remaining days of the season. The model then estimated the number of secondary infected hosts, also known as infectious bites (IB) from one infectious individual via the mosquito vectors. In absence of monitored mosquito data, the model assumed that there would be one mosquito each day of the year. Meteorological data (temperature, rainfall and humidity) from 1 January 2017 to 22 March 2019 were obtained from the Agence Nationale de l'Aviation Civile (ANAC) of Congo. 
Table 1. The biological parameters and the equations used in the model.

\begin{tabular}{ccc}
\hline Traits & Source & Ref \\
\hline Mosquitoes daily survival rate & $\left.\left.\mathrm{e}^{-1 /\left(-4.4+1.31^{*} \text { Tmean }-0.03^{*}(\mathrm{Tmean})\right.}\right)^{\wedge}\right)$ & {$[24]$} \\
\hline Biting rate & $\left(1 /\left(0.0943+0.0043^{*} \mathrm{~T}\right)\right) / 24$ & {$[25]$} \\
\hline Extrinsic incubation period & $(-0.1393+0.008 \mathrm{~T}) / 24$ & {$[26]$} \\
\hline Viremic period & 4 days & {$[26]$} \\
\hline Mosquitoes to human transmission rate & 0.8 & {$[26]$} \\
\hline Human to mosquito transmission rate & 0.8 & {$[26]$} \\
\hline $\begin{array}{l}\text { Probability of finding a susceptible } \\
\text { human host by Aedes spp mosquito }\end{array}$ & 0.5 & \\
\hline
\end{tabular}

Tmean = Daily mean temperature. $\mathrm{T}=$ Hourly temperature.

\subsection{Statistical Analysis}

Statistical analyses were performed using STATA 13.1 Descriptive statistics were used by means of proportions and median (interquartile range). Quantitative data were presented through frequency and percentage.

\section{Results}

\subsection{Patients' Characteristics}

Demographic and clinical characteristics of the patients are reported in Table 2.

Table 2. Characteristics of patients $(N=349)$ by case classification.

\begin{tabular}{|c|c|c|c|c|c|}
\hline Characteristics * & Total $n(\%)$ & Confirmed $n(\%)$ & Suspect $n(\%)$ & Non Case $n(\%)$ & $p$ Value \\
\hline \multicolumn{5}{|l|}{ Department $(N=349)$} & \multirow{4}{*}{0.217} \\
\hline Pointe-Noire & $288(100)$ & $58(20.1)$ & $186(66.6)$ & $44(15.3)$ & \\
\hline Kouilou & $60(100)$ & $25(41.7)$ & $8(13.3)$ & $27(45.0)$ & \\
\hline Other & $1(100)$ & $1(100)$ & 0 & 0 & \\
\hline \multicolumn{5}{|l|}{ Gender $(N=302)$} & \multirow{3}{*}{0.217} \\
\hline Male & $113(100)$ & $25(22.1)$ & $65(57 \cdot 5)$ & $23(20.4)$ & \\
\hline Female & $189(100)$ & 37 (19.6) & $126(66 \cdot 7)$ & $26(13.8)$ & \\
\hline \multicolumn{5}{|l|}{ Age $(N=212)$} & \\
\hline Median (IQR) & $34(13-47)$ & $41(30-49)$ & $34(13-46)$ & $33(13-48)$ & \\
\hline \multicolumn{5}{|l|}{ Age $(N=212)$} & \multirow{5}{*}{0.7} \\
\hline$\leq 5$ years & $4(100)$ & 0 & $3(75.0)$ & $1(25.0)$ & \\
\hline $6-15$ years & $60(100)$ & $2(3.3)$ & $54(90.0)$ & $4(6.7)$ & \\
\hline $16-40$ years & $68(100)$ & $4(5.9)$ & $59(86.8)$ & $5(7.4)$ & \\
\hline$>40$ & $80(100)$ & $6(7.5)$ & $70(87.5)$ & $4(5.0)$ & \\
\hline $\begin{array}{l}\text { Duration of symptoms } \\
(N=248) \text {, Median (IQR) }\end{array}$ & $3(2-4)$ & $3(2-4)$ & $2(1-4)$ & $3(2-5)$ & \\
\hline
\end{tabular}

${ }^{*}$ For each data set, the number of patients with available records is specified in brackets.

During the period between the declaration of the outbreak and 27 March (end of the investigation), 349 suspect patients were reported and samples sent to LNSP. Of these, $288(82.5 \%)$ were residing in the Pointe Noire Department (Figure S1), 60 (17.2\%) in the Kouilou Department and 1 in Dolisie (Niari Department). Of the 349 suspect patients, 84 (24.1\%) were confirmed, 194 (55.6\%) were under investigation and $71(20.3 \%)$ were non-cases. Of the 278 confirmed and under investigation cases, $244(87.8 \%)$ were from Pointe Noire, $33(11.9 \%)$ from Kouilou and one from Dolisie. Of the 84 confirmed cases, $59(70.3 \%)$ were positive at RT-PCR, 18 (21.4\%) were IgM- and IgG-positive and 7 (8.3\%) were 
IgM-only positive. The epidemic curve shows an increase of reported cases after strengthening of the surveillance system during the mission (Figure 1).

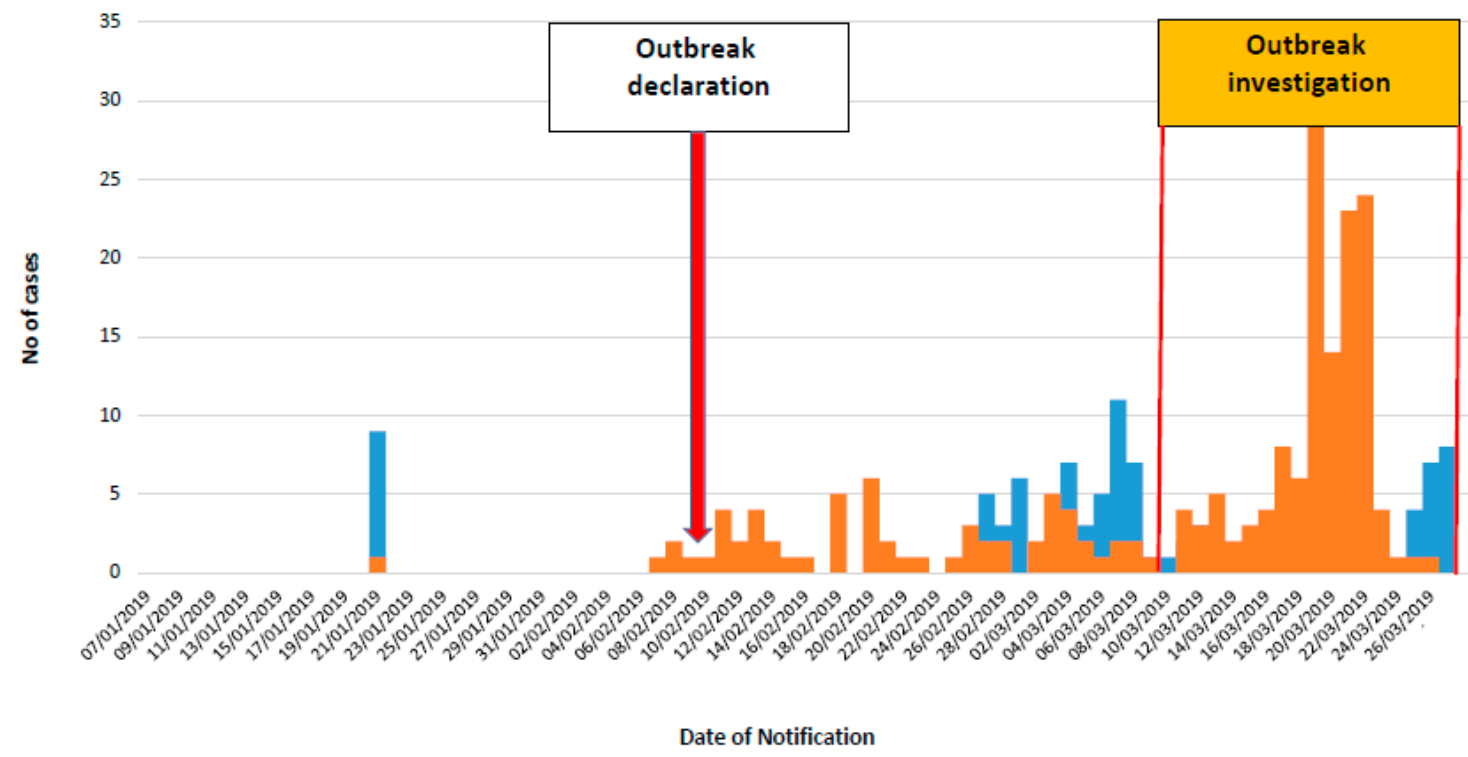

Figure 1. Epidemic curve of confirmed and under investigation cases. The epidemic curve shows an increase of reported cases after strengthening of the surveillance system during the mission (orange bars: cases under investigation, blue bars: confirmed cases).

\subsection{Molecular Characterization}

ML phylogenetic analysis of the two new CHIKV sequences sharing $99.8 \%$ nucleotide identity has been later confirmed by Fritz et al. [24] reporting a strain belonging to the ECSA lineage, clustering with the more recent enzootic ECSA 2 sub-clade and showing A226V mutation.

Figure 2 shows the Bayesian maximum clade credibility tree. Sequences harboring the A226V mutation are highlighted by black dots. The Bayesian tree analysis supports the assignment of both RoC 2019 CHIKV sequences to a unique strain belonging to ECSA 2 sub-clade. Hu/Angola/NIID54/2016 (GenBank accession number: LC259094), a strain isolated in 2016 in Angola [25] lacking the A226V mutation, is the closest related sequence ( $98.9 \%$ nucleotide identity) to both 2019 RoC sequences. The analysis suggests that these strains have a common origin, dating back to around 1973 (95\% HPD 1970-1977), from which they diverged around 1989 (95\% HPD 1985-1994). 


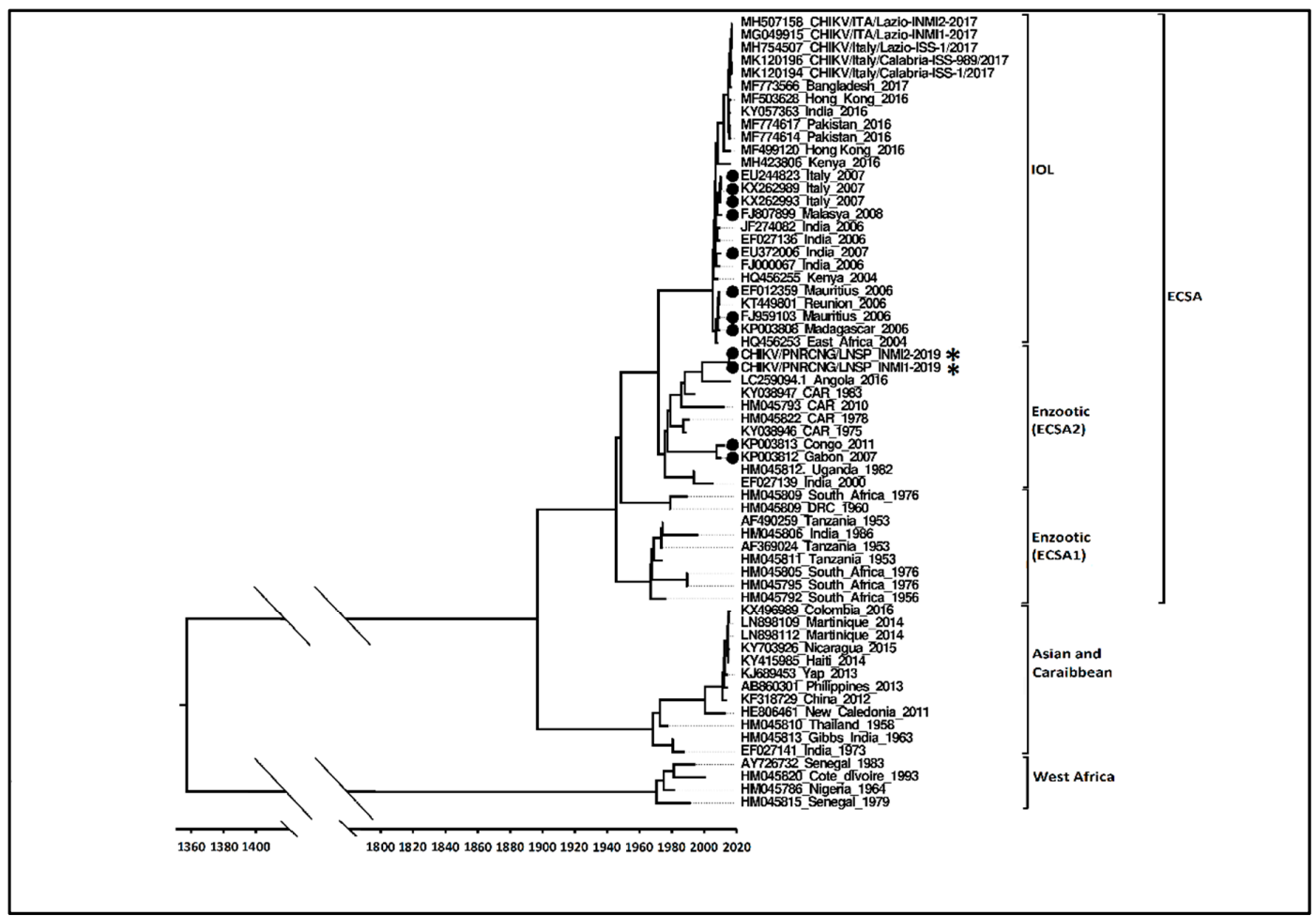

Figure 2. Bayesian maximum clade credibility tree built with full genome sequences of CHIK/PNRCNG/LNSP_INMI1-2019 and CHIK/PNRCNG/LNSP_INMI2-2019 strains highlighted by as an asterisk $(*)$, in the context of 60 full genome sequences representing the 3 major CHIKV lineages: ECSA ( $n=44$, including the Indian Ocean sub-lineage, $n=26$; the IOL sub-lineage includes the Pakistani-Italian 2017 cluster, $n=12$ and the Italian 2007 cluster, $n=3)$, Asia-Caribbean $(n=12)$, and West Africa $(n=4)$. Each record consists of accession number, place and year of detection/isolation. The parameters used in BMCC were mutation model General Time Reversible + G, strict clock model and constant size demographic model. It was tested through MCMC for at least $100 \times 10^{6}$ generations. The bar represents time coalescent in years. Sequences harboring the A226V mutation are highlighted by black dots.

SAn extensive analysis of the pattern of mutations carried by the $2019 \mathrm{RoC}$ sequences, among those mutations reported to affect vectorial competence of CHIKV [5,12,26], is shown in Table 3.

The strains not carrying the A226V mutation show a high degree of variation, with mutations located at multiple sites along the ORF-1 and ORF-2 polyproteins. In contrast, the strains carrying the A226V mutation show less variability and share a common mutational pattern. In addition to the considered amino acid positions, the CHIK/PNRCNG/LNSP_INMI1-2019 and CHIK/PNRCNG/LNSP_INMI2-2019 strains carry additional unique mutations, in particular E2-T126M and E2-H351N, which are not present in any of the GenBank sequences archived so far. 
Table 3. Mutational profile of CHIK/PNRCNG/LNSP_INMI1-2019 and CHIK/PNRCNG/LNSP_INMI2-2019 (in bold characters) compared to the 60 full genome sequences included in the phylogenetic analysis (see Figure 2). The upper part of the table includes sequences carrying the original amino acid (A) at position E1-226; the lower part includes sequences with the E1-A226V mutation. The 1953 Tanzanian strain (S27), used as reference, is in the first row.

\begin{tabular}{|c|c|c|c|c|c|c|c|c|c|c|c|c|c|c|c|c|c|c|c|c|c|c|}
\hline \multirow{4}{*}{$\begin{array}{c}\text { Polyprotein } \\
\text { Amino acid position } \\
\text { Protein } \\
\text { Amino acid position }\end{array}$} & \multicolumn{8}{|c|}{ ORF 1} & \multicolumn{14}{|c|}{ ORF 2} \\
\hline & \multirow{2}{*}{$\begin{array}{c}476 \\
\text { nsP1 } \\
\end{array}$} & 665 & 680 & 1705 & 1857 & 1918 & 1948 & 214 & 62 & 404 & 489 & 530 & 589 & 637 & 700 & 711 & 1020 & 1035 & 1078 & 1093 & 1126 & 1131 \\
\hline & & \multicolumn{2}{|c|}{ nsP2 } & \multicolumn{2}{|c|}{ nsP3 } & \multicolumn{3}{|c|}{ nSP4 } & C & \multicolumn{7}{|c|}{ E2 } & \multicolumn{6}{|c|}{ E1 } \\
\hline & 476 & 130 & 145 & 372 & 524 & 55 & 85 & 281 & 62 & 79 & 164 & 205 & 264 & 312 & 375 & 386 & 211 & 226 & 269 & 284 & 317 & 322 \\
\hline \multicolumn{23}{|c|}{ Strains non carrying the A226V mutation } \\
\hline AF369024 Tanzania 1953 & $\mathbf{P}$ & $\mathbf{H}$ & E & D & $\mathbf{R}$ & $\mathrm{S}$ & $\mathbf{R}$ & $\mathbf{V}$ & $\mathbf{R}$ & G & A & G & $\mathrm{V}$ & $\mathbf{T}$ & $\mathrm{S}$ & $\mathrm{V}$ & $\mathbf{K}$ & A & $\mathbf{M}$ & D & I & $\mathbf{V}$ \\
\hline LC259094 Angola 2016 & & & & & & & & & & $\mathrm{E}$ & $\mathrm{T}$ & & & & & & & & $\mathrm{V}$ & & & A \\
\hline MF503628 Hong Kong 2016 & & $\mathrm{Y}$ & $\mathrm{D}$ & & & $\mathrm{N}$ & & & & E & $\mathrm{T}$ & & A & $\mathrm{M}$ & $\mathrm{T}$ & A & $\mathrm{E}$ & & $\mathrm{V}$ & $\mathrm{E}$ & & A \\
\hline EF027136 India 2006 & & & & & & & & & & E & $\mathrm{T}$ & & & $\mathrm{M}$ & $\mathrm{T}$ & A & & & $\mathrm{V}$ & E & & A \\
\hline JF274082 India 2006 & & & & & $\mathrm{R}$ & & & & & E & $\mathrm{T}$ & & & $\mathrm{M}$ & $\mathrm{T}$ & A & & & $\mathrm{V}$ & E & & A \\
\hline FJ000067 India 2006 & & & & & & & & & & E & $\mathrm{T}$ & & & $\mathrm{M}$ & $\mathrm{T}$ & A & & & $\mathrm{V}$ & E & & A \\
\hline EF027139 India 2000 & & & & & $\mathrm{R}$ & & & & & E & $\mathrm{T}$ & & & & & & & & $\mathrm{V}$ & & & A \\
\hline HM045793 CAR?? & & & & & & & & & & E & $\mathrm{T}$ & & & & & & & & $\mathrm{V}$ & & & A \\
\hline AF490259 Tanzania 1953 & & & & & $\mathrm{R}$ & & & & & E & & & & & & & & & & & & . \\
\hline HM045813 Gibbs India 1963 & . & & & & & & & & & E & & $\mathrm{D}$ & & & & & E & & & & & A \\
\hline KY703926 Nicaragua 2015 & & & & & & & & & & E & & $\mathrm{D}$ & & & & & $\mathrm{E}$ & & & & & A \\
\hline KJ689453 Yap 2013 & & & & & & & & & & E & & $\mathrm{D}$ & & & & & E & & & & & A \\
\hline KY415985 Haiti 2014 & & & & & & & & & & E & & $\mathrm{D}$ & & & & & E & & & & & A \\
\hline LN898109 Martinique 2014 & & & & & & & & & & E & & $\mathrm{D}$ & & & & & E & & & & & A \\
\hline LN898112 Martinique 2014 & & & & & & & & & & E & & $\mathrm{D}$ & & & & & E & & & & & A \\
\hline HM045786 Nigeria 1964 & & & & & & & G & & & E & & & & & & & & & $\mathrm{V}$ & & & A \\
\hline AY726732 Senegal 1983 & & & & & & & G & & & E & & & & & & & & & $\mathrm{V}$ & & & A \\
\hline HM045809 South Africa 1976 & $\mathrm{Q}$ & & & & & & & & & E & & & & & & & & & $\mathrm{V}$ & & & A \\
\hline HM045795 South Africa 1976 & & & & & & & & & & $\mathrm{E}$ & & & & & & & & & & & & $\mathrm{A}$ \\
\hline KY057363 India 2016 & & $\mathrm{Y}$ & $\mathrm{D}$ & & & $\mathrm{N}$ & & & & E & $\mathrm{T}$ & & A & $\mathrm{M}$ & $\mathrm{T}$ & A & E & . & $\mathrm{V}$ & E & $\mathrm{V}$ & A \\
\hline HM045811 Tanzania 1953 & & & & & & & & & & $\mathrm{E}$ & & & & & & & & & & & & A \\
\hline HM045821 Senegal 1963 & & & & & $\mathrm{R}$ & & & & & & & & & & & & & & & & & . \\
\hline HM045810 Thailand 1958 & & & & & & & & & & E & & $\mathrm{D}$ & & & & & E & & . & & & A \\
\hline HM045815 Senegal 1979 & & & & & & & G & & & E & & . & & & & & & & $\mathrm{V}$ & & & A \\
\hline HM045820 Cote dIvoire 1993 & & & & & & & G & & & $\mathrm{E}$ & & . & & & & & & & $\mathrm{V}$ & & & A \\
\hline AB860301 Philippines 2013 & & & & & & & & & & $\mathrm{E}$ & & $\mathrm{D}$ & & & & & E & & & & & A \\
\hline KX496989 Colombia 2016 & & & & & & & & & & $\mathrm{E}$ & & $\mathrm{D}$ & & & & & E & & & & & A \\
\hline EF027141 India 1973 & & & & & & & & & & $\mathrm{E}$ & & $\mathrm{D}$ & & & & & $\mathrm{E}$ & & & & & A \\
\hline HE806461 New Caledonia 2011 & & & & & & & & & & E & & $\mathrm{D}$ & & & & & $\mathrm{E}$ & & & & & A \\
\hline KF318729 China 2012 & & & & & & & & & & E & & $\mathrm{D}$ & & & & & E & & & & & A \\
\hline HQ456255 Kenya 2004 & & & & & & & & & & $\mathrm{E}$ & $\mathrm{T}$ & & & $\mathrm{M}$ & $\mathrm{T}$ & A & & & $\mathrm{V}$ & E & & A \\
\hline
\end{tabular}


Table 3. Cont.

\begin{tabular}{|c|c|c|c|c|c|c|c|c|c|c|c|c|c|c|c|c|c|c|c|c|}
\hline Polyprotein & & & & & & & & & & & & & & & & & & & & \\
\hline \multicolumn{21}{|c|}{ Strains non carrying the A226V mutation } \\
\hline $\begin{array}{l}\text { MG049915 } \\
\text { CHIKV/ITA/Lazio-INMI1-2017 }\end{array}$ & Y & $\mathrm{D}$ & $\mathrm{E}$ & & $\mathrm{N}$ & & $\mathrm{C}$ & $\mathrm{E}$ & $\mathrm{T}$ & $\mathrm{S}$ & A & M & $\mathrm{T}$ & A & E & & $\mathrm{V}$ & $\mathrm{E}$ & $\mathrm{V}$ & A \\
\hline $\begin{array}{l}\text { MH507158 } \\
\text { CHIKV/ITA/Lazio-INMI2-2017 }\end{array}$ & Y & $\mathrm{D}$ & $\mathrm{E}$ & & $\mathrm{N}$ & & $\mathrm{C}$ & E & $\mathrm{T}$ & $\mathrm{S}$ & A & M & $\mathrm{T}$ & A & E & & $\mathrm{V}$ & $\mathrm{E}$ & $\mathrm{V}$ & A \\
\hline MF774617 Pakistan-07/2016 & $\mathrm{Y}$ & $\mathrm{D}$ & & & $\mathrm{N}$ & I & & E & $\mathrm{T}$ & & A & $\mathrm{M}$ & $\mathrm{T}$ & A & E & & $\mathrm{V}$ & $\mathrm{E}$ & $\mathrm{V}$ & A \\
\hline MF774614 Pakistan-04/2016 & $\mathrm{Y}$ & $\mathrm{D}$ & & & $\mathrm{N}$ & I & & E & $\mathrm{T}$ & & A & $\mathrm{M}$ & $\mathrm{T}$ & A & E & & $\mathrm{V}$ & $\mathrm{E}$ & $\mathrm{V}$ & A \\
\hline MF773566 Bangladesh 2017 & Y & $\mathrm{D}$ & $\mathrm{E}$ & & $\mathrm{N}$ & . & & E & $\mathrm{T}$ & $\mathrm{s}$ & A & $\mathrm{M}$ & $\mathrm{T}$ & A & E & & $\mathrm{V}$ & $\mathrm{E}$ & $\mathrm{V}$ & A \\
\hline MF499120 Hong Kong 2016 & $\mathrm{Y}$ & & & & & & & $\mathrm{E}$ & $\mathrm{T}$ & & $\mathrm{A}$ & M & $\mathrm{T}$ & A & $\mathrm{E}$ & & V & $\mathrm{E}$ & $\mathrm{V}$ & A \\
\hline HM045805 South Africa 1976 & & & & & & & & $\mathrm{E}$ & & & $x$ & & & & & & & & & A \\
\hline HM045792 South Africa 1956 & & & & & & & & E & & & & & & & & & & & & A \\
\hline MH423806 Kenya 2016 & & & & & & & & $\mathrm{E}$ & $\mathrm{T}$ & & A & $\mathrm{M}$ & $\mathrm{T}$ & A & E & & $\mathrm{V}$ & $\mathrm{E}$ & & A \\
\hline HQ456253 East Africa 2004 & & & & & & & & $\mathrm{E}$ & $\mathrm{T}$ & & & $\mathrm{M}$ & $\mathrm{T}$ & $\mathrm{A}$ & & & V & $\mathrm{E}$ & & A \\
\hline HM045809 DRC 1960 & & & & & & & & E & & & & & & & & & $\mathrm{V}$ & & & A \\
\hline HM045822 CAR 1978 & & & & & & & & E & $\mathrm{T}$ & & & & & & & & $\mathrm{V}$ & & & A \\
\hline KY038946 CAR 1975 & & & & & & & & E & $\mathrm{T}$ & & & & & & & & $\mathrm{V}$ & & & A \\
\hline KY038947 CAR 1983 & & & & & & & & E & $\mathrm{T}$ & & & & & & & & $\mathrm{V}$ & & & A \\
\hline HM045812. Uganda 1982 & & & & & & & & $\mathrm{E}$ & $\mathrm{T}$ & & & & & & & & $\mathrm{V}$ & & & A \\
\hline $\begin{array}{l}\text { MK120194 } \\
\text { CHIKV/Italy/Calabria-ISS-1/2017 }\end{array}$ & $\mathrm{Y}$ & $\mathrm{D}$ & $\mathrm{E}$ & & $\mathrm{N}$ & & $\mathrm{C}$ & E & $\mathrm{T}$ & S & A & M & $\mathrm{T}$ & A & $\mathrm{E}$ & & $\mathrm{V}$ & $\mathrm{E}$ & $\mathrm{V}$ & A \\
\hline $\begin{array}{l}\text { MK120196 } \\
\text { CHIKV/Italy/Calabria-ISS-989/2017 }\end{array}$ & $\mathrm{Y}$ & $\mathrm{D}$ & $\mathrm{E}$ & & $\mathrm{N}$ & & $\mathrm{C}$ & E & $\mathrm{T}$ & $\mathrm{S}$ & $\mathrm{A}$ & $\mathrm{M}$ & $\mathrm{T}$ & A & E & & $\mathrm{V}$ & $\mathrm{E}$ & $\mathrm{V}$ & A \\
\hline $\begin{array}{l}\text { MH754507 } \\
\text { CHIKV/Italy/Lazio-ISS-1/2017 }\end{array}$ & Y & $\mathrm{D}$ & $\mathrm{E}$ & & $\mathrm{N}$ & & $\mathrm{C}$ & E & $\mathrm{T}$ & S & $\mathrm{A}$ & M & $\mathrm{T}$ & A & E & & $\mathrm{V}$ & $\mathrm{E}$ & $\mathrm{V}$ & A \\
\hline \multicolumn{21}{|c|}{ Strains carryng the A226V mutation } \\
\hline CHIK/PNRCNG/LNSP_INMI2-2019 & & & & & & & & E & $\mathrm{T}$ & D & & & & & & $\mathrm{V}$ & $\mathrm{V}$ & & & A \\
\hline CHIK/PNRCNG/LNSP_INMI1-2019 & & & & & & & & E & $\mathrm{T}$ & D & & & & & & $\mathbf{V}$ & $\mathbf{v}$ & & & $\mathbf{A}$ \\
\hline KT449801 Reunion 2006 & & & & & & & & E & $\mathrm{T}$ & & & $\mathrm{M}$ & $\mathrm{T}$ & A & & $\mathrm{V}$ & $\mathrm{V}$ & E & & $\mathrm{A}$ \\
\hline EU244823 Italy 2007 & & & & & & & & E & $\mathrm{T}$ & & & $\mathrm{M}$ & $\mathrm{T}$ & A & & $\mathrm{V}$ & $\mathrm{V}$ & E & & A \\
\hline KX262993 Italy 2007 & & & & & & & & E & $\mathrm{T}$ & & & $\mathrm{M}$ & $\mathrm{T}$ & A & & $\mathrm{V}$ & $\mathrm{V}$ & $\mathrm{E}$ & & A \\
\hline KX262989 Italy 2007 & & & & $\mathrm{R}$ & & & & $\mathrm{E}$ & $\mathrm{T}$ & & & $\mathrm{M}$ & $\mathrm{T}$ & A & & $\mathrm{V}$ & $\mathrm{V}$ & $\mathrm{E}$ & & A \\
\hline KP003813 Congo 2011 & & & & & & & & E & $\mathrm{T}$ & & & & & & & $\mathrm{V}$ & $\mathrm{V}$ & & & A \\
\hline KP003812 Gabon 2007 & & & & & & & & E & $\mathrm{T}$ & & & & & & & $\mathrm{V}$ & $\mathrm{V}$ & & & A \\
\hline FJ807899 Malasya 2008 & & & & & & & & $\mathrm{E}$ & $\mathrm{T}$ & & & $\mathrm{M}$ & $\mathrm{T}$ & A & & $\mathrm{V}$ & V & $\mathrm{E}$ & & $\mathrm{A}$ \\
\hline EU372006 India 2007 & & & & & & & & E & $\mathrm{T}$ & & & $\mathrm{M}$ & $\mathrm{T}$ & A & & $\mathrm{V}$ & $\mathrm{V}$ & E & & A \\
\hline FJ959103 Mauritius 2006 & & & & & & & & E & $\mathrm{T}$ & & & $\mathrm{M}$ & $\mathrm{T}$ & A & & $\mathrm{V}$ & $\mathrm{V}$ & $\mathrm{E}$ & & A \\
\hline EF012359 Mauritius 2006 & & & & & & & & $\mathrm{E}$ & $\mathrm{T}$ & & & M & $\mathrm{T}$ & A & & $\mathrm{V}$ & V & $\mathrm{E}$ & & A \\
\hline KP003808 Madagascar 2006 & & & & $\mathrm{R}$ & & & & $\mathrm{E}$ & $\mathrm{T}$ & & & M & $\mathrm{T}$ & $\mathrm{A}$ & & $\mathrm{V}$ & V & $\mathrm{E}$ & & A \\
\hline
\end{tabular}




\subsection{Predictive Model}

\subsubsection{Infectious Bites}

We estimated IB for the period of 2017-2018 and in the first 2 months of 2019. The pattern was similar for the years 2017, 2018, and relevant 2019 period (Figure 3). If weather pattern remains similar to the previous two years, the current epidemic will continue until July, then the transmission will drop down for a couple of months and will increase again by early November. A plausible explanation for the absence of disease in 2018, despite a similar pattern of IB through 2017-2019 predicted by the model, is that the pathogen could have been absent until late 2018, when it could have been introduced by an infected migrant or spill over from a sylvatic host. This explanation is consistent with the phylogenetic analysis showing no evidence of evolving pattern from the strain previously circulating in the country (2011 RoC strain).

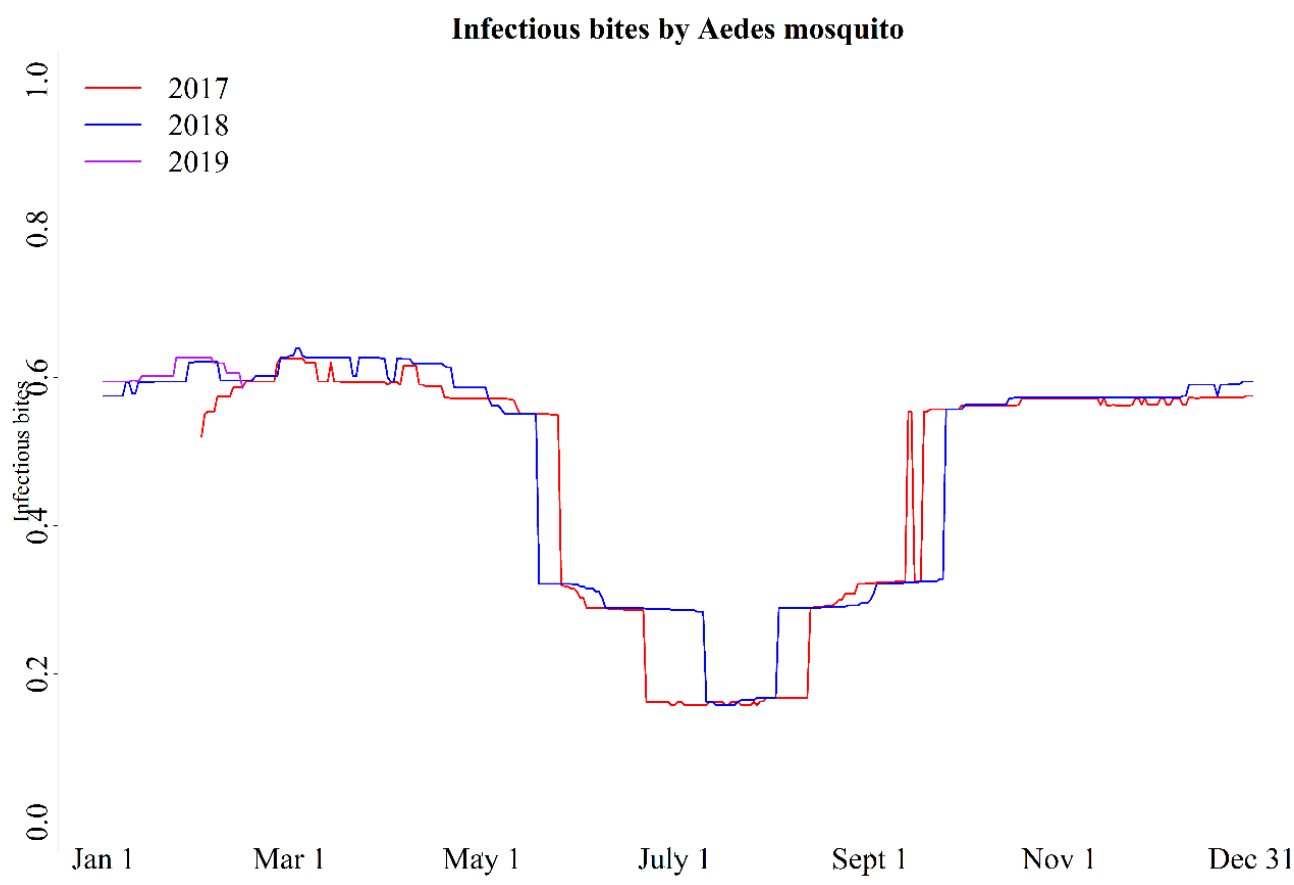

Figure 3. The Infectious bites of Aedes mosquito estimated from a mathematical model considering that mosquitoes were infected with chikungunya virus and exposed to environmental temperature, which was similar to the recorded meteorological temperature at a local weather station at Pointe-Noire, Republic of Congo.

\subsubsection{Entomological Investigations}

During the first week of March 2019, 215 adult mosquitoes were collected in different villages of Kouilou and Pointe-Noire districts. Further, on the third week of March, 38 adult mosquitoes were collected in Diosso (Kouilou department), of which 24 were Ae. albopictus, 2 Ae. aegypti and 12 other Culicinae spp. For PCR analysis purposes, the insects were pooled by collection site (Table 4).

A total of 100 houses were inspected for the presence of potential mosquitos breeding sites and for immature mosquitoes (larvae and pupae) outside the houses. Of these, 88 (88\%) houses had water-holding containers in their surroundings including plastic containers, tires, water tanks and swamps. Water holding containers in 94 houses were found to harbor mosquito pupae. The overall containers, houses and Breteaux indices were $84 \%, 92 \%$ and $8.6 \%$, respectively. 
Table 4. Mosquitoes collected by collection period, location, species and RT-PCR results.

\begin{tabular}{|c|c|c|c|c|}
\hline Collection Time & Department & Village/Quartier & Identified Species $(n)$ & RT-PCR \\
\hline \multirow{5}{*}{ 1st week of March } & \multirow{5}{*}{ Kouilou } & Nkoungou & Ae. albopictus (18) & Positive \\
\hline & & Diosso & Ae. albopictus (37) & Negative \\
\hline & & Mengo & Ae. albopictus (8) & Negative \\
\hline & & Matombi & Ae. albopictus (16) & Negative \\
\hline & & Mabindou & Ae. albopictus (25) & Negative \\
\hline \multirow{4}{*}{ 1st week of March } & \multirow{4}{*}{ Pointe Noire } & & Ae. albopictus (34) & Negative \\
\hline & & & Ae. aegypti (20) & Negative \\
\hline & & Tchiamba Nzassi & Ae. albopictus (47) & Negative \\
\hline & & Siafoumou & Ae. albopictus (10) & Negative \\
\hline \multirow{3}{*}{ 3rd week of March } & \multirow{3}{*}{ Kouilou } & \multirow{3}{*}{ Diosso } & Ae. aegypti (2) & Negative \\
\hline & & & Ae. albopictus (24) & Negative \\
\hline & & & Culicinae spp (12) & Negative \\
\hline
\end{tabular}

\section{Discussion}

Our study provides important insights on the epidemiological, virological and entomological characteristics of the 2019 CHIK outbreak in RoC, through a ONE HEALTH south-north multidisciplinary taskforce investigation. Patients' demographic characteristics show a higher proportion of females probably due to their routine housekeeping activities, where most of the breeding sites are located in small containers for water collection. The median age is higher than in 2011 outbreak (34 vs 29 years) [13], and the proportion of cases increases with age, with children under 5 years old almost not affected. Age is a proxy-factor for specific behaviors causing higher exposure to Ae. albopictus bites (i.e., staying outdoors during daytime) or less tendency toward individual protection (i.e., use of repellents) in elderly people. Elderly people are also more likely to show symptoms and to access health structures than young people. The age profile could be also explained by the high susceptibility of the population with no herd immunity, supporting the hypothesis of absent, or very scarce circulation of the virus in the affected departments in the previous years. The median time between onset of symptoms and notification is much lower than in previous African and European outbreaks [15]. This could be related to a more severe initial symptomology, mainly joint pain, which brought patients to rapidly attend a health facility. The clinical presentation should be better clarified through dedicated cohort studies.

The phylogenetic analysis, based on near full genome sequences obtained from two patients living in Pointe Noire District, shows that the strain involved in this outbreak belongs to the ECSA enzootic lineage, specifically to a recent cluster, also called ECSA 2 [13]. This cluster includes CHIKV strains currently circulating in Central Africa and differentiates from the ECSA 1 also for the presence of the A226V mutation in some strains. Same findings were obtained from a patient in Diosso in the District of Kouilou [24]. The closest related is a strain isolated in 2016 in Angola, that lacks the A226V mutation, from which divergence seems to have occurred around 1990. In addition, RoC 2019 sequences belong to the same sub-clade of the 2011 RoC outbreak strain $[13,14]$ but are placed on a distinct branch of the phylogenetic tree. A lower degree of variability was observed between strains carrying the A226V mutation and those that do not. In addition, two novel mutations, E2-T126M and E2-H351N, render the RoC 2019 strain unique. Adaptive changes due to other different mutations in E2 glycoprotein have been previously reported [27,28], and further studies are needed to explore the effect on viral infectivity and transmission possibly linked to the observed E2 mutations. The replacement of Ae. aegypti by Ae. albopictus already noticed previously (i.e., Gabon 2007 and Cameroon 2006) was also reported in $\mathrm{RoC}$ where the invasive species are predominant over the native ones in all locations except Brazzaville, suggesting that Ae. albopictus is displacing Ae. aegypti across RoC [29]. The 2019 RoC strain, like the strains from Gabon and Cameroon outbreaks (Chik_Cam_7079, GenBank_EF051584) [9,10], originates from the Central-African lineage, and it is distinct from the contemporary Indian/Indian 
Ocean isolates, but in contrast to original Central-African strains (transmitted by Ae. aegypti), it carries the $\mathrm{A} 226 \mathrm{~V}$ mutation. This implies an independent adaptive mutation in response to vector replacement (Ae. albopictus vs Ae. aegypti), confirming previous findings $[5,11,26]$. The virus might have been recently introduced into the area or be endemic in a sylvatic cycle, without spill over to humans in the years 2017-2018. It is important to evaluate the possibility of an endemic circulation of CHIKV at the human-animal interface. The presence of CHIKV should be investigated in wild (non-human primates, rodents, etc.), domestic animals (cows, goats) and wild-type vectors (Ae. africanus, Ae. furcifer and Ae. taylori). Human exposure should be assessed through longitudinal seroprevalence studies at the human-animal interface. The model highlights a suitable environment and shows potential for a CHIK outbreak in all studied years (2017, 2018 and first 2 months of the year 2019). The absence of outbreaks in previous years may indicate mere absence of the pathogen in the country or a low level of transmission into the vector not sufficient to spill over into the community. Our phylogenetic characterization is compatible with the introduction from other Central African countries. The virus could have been introduced from other endemic areas through the seaport city of Pointe Noire. Alternatively, the virus could have circulated among the wildlife for long before to reach the threshold of prevalence needed to cause human epidemics. Diosso, one of the first villages reporting CHIK cases in 2019, is an ecological hub for a potential spillover event, being surrounded on three sides by a large canyon, named Gorge of Diosso, visited by local and international visitors and inhabited by several animal species including pigs, bats, rats, mice, shrews, porcupine, snakes, squirrels and monkeys. We suggest further exploration of the role of wildlife in the CHIK sylvatic cycles. In Senegal, non-human primates were found to play an important role in maintenance of CHIKV in wildlife [30]. The predominance of Ae. Albopictus as dominant vector in the study area could be due to the specific ecological requirements of the two species. While Ae. aegypti prefers to occupy human houses (close and/or inside the human dwellings), Ae. albopictus prefers vegetation and forest areas more protected by control interventions. The entomological indexes where all very high, underlying the importance of community education about control of mosquito activity.

The limitations of the study include the scarce proactive countrywide human and entomological surveillance during the mission and the limited precision of the geolocalization, since data about patients' residence were referred to a general zone (village or quartier). Strengthening the ongoing surveillance system is key for evaluating the spread of the disease, allocating the appropriate resources for outbreak response, evaluating clinical management of patients, advising on vector control measures and guiding preparedness for future outbreaks. Implementation of an active surveillance through community-based activities is a key issue. Reporting of suspect cases by community health workers, door-to-door case findings and subsequent diagnosis should be regularly implemented. The integration of arboviruses surveillance into the well-established and ongoing surveillance activities for malaria should be taken into consideration exploiting experience, tools and model from malaria surveillance. In addition, surveillance and research into the sylvatic reservoirs of known and unknown arboviruses is key in understanding the spatio-temporal dynamics of CHIKV and potentially newly emerging arboviruses, as is the case in the neighboring DRC where Dengue virus and CHIKV were found during investigation of a yellow fever outbreak [31].

\section{Conclusions}

The PANDORA model of south-north cooperation and the ONE HEALTh approach to tackle the CHIKV outbreak in $\mathrm{RoC}$ was successful allowing a fast, innovative and functional investigation and giving rapid and prompt insights into the outbreak's dynamics. This paves the way for further collaborations among the involved stakeholders for short-, medium- and long-term epidemic response and preparedness plans.

Supplementary Materials: The following are available online at http://www.mdpi.com/1999-4915/12/9/1020/s1, Figure S1: Geolocalization of suspected and confirmed cases from Pointe-Noire, Table S1: SANGER Primers used for RT-PCR and sequencing, Table S2: MinION Primers used for RT-PCR and sequencing. 
Author Contributions: G.I., A.Z., F.N., R.K., M.R.C. and F.V. initiated and coordinated the PANDORA-ID-NET CHIKV consortium taskforce group investigation. C.C., N.H., M.I., S.L., C.M. and M.R. conducted the investigations. F.C. (Fabrizio Carletti), F.C. (Francesca Colavita), C.E.M.G., F.M., E.G. and B.B. performed all the laboratory analyses. M.P.A.C.-M., L.K., B.U.J., C.P., S.D.-D., L.M., V.M., R.F., S.S., C.M.-F., B.E.-P., S.G.-M., E.V.N., P.K.T., E.N., V.P., A.D.C. and J.L.M. contributed to data analyses, interpretation and writing of the manuscript. All authors have read and agreed to the published version of the manuscript.

Funding: PANDORA-ID-NET Consortium (EDCTP Reg/Grant RIA2016E-1609) and EPIRISK-Ebov (EDCTP Regç/Grant RIA 2018EF-2082) Consortium funded by the European and Developing Countries Clinical Trials Partnership (EDCTP2) programme, which is supported under Horizon 2020, the European Union's Framework Programme for Research and Innovation. Italian Ministry of Health-Ricerca Corrente-Linea 1, and the Division of Intramural Research of the NIAID.

Acknowledgments: We thank the Ministry of Health and the Ministry of Science and Technology for the great support provided to the investigation and for their devotion and commitment towards a better health in the Republic of Congo. Authors who are part of PANDORA-ID-NET Consortium (EDCTP Reg/Grant RIA2016E-1609) funded by the European and Developing Countries Clinical Trials Partnership (EDCTP2) programme, which is supported under Horizon 2020, the European Union's Framework Programme for Research and Innovation. A.Z. is in receipt of a National Institutes of Health Research (NIHR) senior investigator award and the PANDORA-ID-NET. F.N. and A.Z. acknowledge support from EDCTP (CANTAM2). F.V. and G.I. acknowledge financial support by the Italian Ministry of Health, grants to Ricerca Corrente linea 1 to National Institute for Infectious Diseases, Lazzaro Spallanzani, IRCCS. F.N., C.M.-F., B.E.-P., E.V.N. and S.G.-M. are part of the EPIRISK EBov Consortium who provided partial support to this study. V.M., B.F. and S.F. are supported by the Division of Intramural Research of the NIAID. We are grateful to L'Agence Nationale de l'Aviation Civile (ANAC) for proving us the meteorological data for the period of January 2017 to March 2019. PANDORA-ID-NET Consortium Chikungunya Outbreak Group Taskforce: Kuisma Eeva, Ibata Francky, Ibata Mbani Pascal, Mayinda Mboungou Franc Astyanax, Mbongo Guy Abel, Paka Alexandre Honoré, Honorati Masanja, Solomon Mwakasungula, Osman Dar, Ben Quayle, Sayoki Mfinanga, Esther Ndegaya, Alexei Yavlinsky, Rashid Ansumana, Sara Edwards, Lia Arruda, Linzy Elton, Matthew Bates, John Tembo, Danny Asogun and Timothy D McHugh.

Conflicts of Interest: All authors have an interest in infectious disease outbreaks. All authors declare no conflict of interest.

\section{References}

1. Zumla, A.; Ippolito, G.; McCloskey, B.; Bates, M.; Ansumana, R.; Heymann, D.; Kock, R.; Ntoumi, F. Enhancing preparedness for tackling new epidemic threats. Lancet Respir. Med. 2017, 5, 606-608. [CrossRef]

2. Ippolito, G.; Lanini, S.; Brouqui, P.; di Caro, A.; Vairo, F.; Abdulla, S.; Fusco, F.M.; Krishna, S.; Capobianchi, M.R.; Kyobe-Bosa, H.; et al. Ebola: Missed opportunities for Europe-Africa research. Lancet Infect. Dis. 2015, 15, 1254-1255. [CrossRef]

3. Vairo, F.; Ippolito, G.; Ntoumi, F.; Zumla, A. Chikungunya-Epidemiology, Pathogenesis, Clinical Features, Management and Prevention. Infect. Dis. Clin. N. Am. 2019, in press.

4. Powers, A.M.; Brault, A.C.; Tesh, R.B. Re-emergence of Chikungunya and O'nyong-nyong viruses: Evidence for distinct geographical lineages and distant evolutionary relationships. J. Gen. Virol. 2000, 81, 471-479. [CrossRef] [PubMed]

5. Volk, S.M.; Chen, R.; Tsetsarkin, K.A.; Adams, A.P.; Garcia, T.I.; Sall, A.A.; Nasar, F.; Schuh, A.J.; Holmes, E.C.; Higgs, S.; et al. Genome-scale phylogenetic analyses of chikungunya virus reveal independent emergences of recent epidemics and various evolutionary rates. J. Virol. 2010, 84, 6497-6504. [CrossRef]

6. Mourya, D.T.; Thakare, J.R.; Gokhale, M.D.; Powers, A.M.; Hundekar, S.L.; Jayakumar, P.C.; Bondre, V.P.; Shouche, Y.S.; Padbidri, V.S. Isolation of chikungunya virus from Aedes aegypti mosquitoes collected in the town of Yawat, Pune District, Maharashtra State. India Acta Virol. 2001, 45, 305-309.

7. Weaver, S.C.; Forrester, N.L. Chikungunya: Evolutionary history and recent epidemic spread. Antivir. Res. 2015, 120, 32-39. [CrossRef]

8. Kraemer, M.U.G.; Sinka, M.E.; Duda, K.A.; Mylne, A.Q.N.; Shearer, F.M.; Barker, C.M.; Moore, C.G.; Carvalho, R.G.; Coelho, G.E.; van Bortel, W.; et al. The global distribution of the arbovirus vectors Aedes aegypti and Ae. albopictus. eLife 2015, 4, e08347. [CrossRef]

9. Peyrefitte, C.N.; Rousset, D.; Pastorino, B.A.M.; Pouillot, R.; Bessaud, M.; Tock, F.; Mansaray, H.; Merle, O.L.; Pascual, A.M.; Paupy, C.; et al. Chikungunya virus, Cameroon, 2006. Emerg. Infect. Dis. 2007, 13, 768-771. [CrossRef] 
10. Leroy, E.M.; Nkoghe, D.; Ollomo, B.; Nze-Nkogue, C.; Becquart, P.; Grard, G.; Pourrut, X.; Charrel, R.; Moureau, G.; Ndjoyi-Mbiguino, A.; et al. Concurrent Chikungunya and dengue virus infections during simultaneous outbreaks, Gabon, 2007. Emerg. Infect. Dis. 2009, 15, 591-593. [CrossRef]

11. De Lamballerie, X.; Leroy, E.; Charrel, R.N.; Ttsetsarkin, K.; Higgs, S.; Gould, E.A. Chikungunya virus adapts to tiger mosquito via evolutionary convergence: A sign of things to come? Virol. J. 2008, 5, 33. [CrossRef] [PubMed]

12. Tsetsarkin, K.A.; Vanlandingham, D.L.; McGee, C.E.; Higgs, S. A single mutation in chikungunya virus affects vector specificity and epidemic potential. PLoS Pathog. 2007, 3, e201. [CrossRef] [PubMed]

13. Moyen, N.; Thiberville, S.; Pastorino, B.; Nougairede, A.; Thirion, L.; Mombouli, J.; Dimi, Y.; Leparc-Goffart, I.; Capobianchi, M.R.; Lepfoundzou, A.D.; et al. First reported chikungunya fever outbreak in the republic of Congo, 2011. PLoS ONE 2014, 9, e115938. [CrossRef]

14. Mombouli, J.V.; Bitsindou, P.; Elion, D.O.A.; Grolla, A.; Feldmann, H.; Niama, F.R.; Parra, H.; Munster, V.J. Chikungunya virus infection, Brazzaville, Republic of Congo, 2011. Emerg. Infect. Dis. 2013, 19, 1542-1543. [CrossRef] [PubMed]

15. Vairo, F.; Mammone, A.; Lanini, S.; Nicastri, E.; Castilletti, C.; Carletti, F.; Puro, V.; di Lallo, D.; Panella, V.; Varrenti, D.; et al. Local transmission of chikungunya in Rome and the Lazio region, Italy. PLoS ONE 2018, 13, e0208896. [CrossRef]

16. Carletti, F.; Marsella, P.; Colavita, F.; Meschi, S.; Lalle, E.; Bordi, L.; di Lallo, D.; Panella, V.; di Caro, A.; Nicastri, E.; et al. Full-Length Genome Sequence of a Chikungunya Virus Isolate from the 2017 Autochthonous Outbreak, Lazio Region, Italy. Genome Announc. 2017, 5, e01306-17. [CrossRef]

17. Khan, A.H.; Morita, K.; Parquet Md Mdel, C.; Hasebe, F.; Mathenge, E.G.; Igarashi, A. Complete nucleotide sequence of chikungunya virus and evidence for an internal polyadenylation site. J. Gen. Virol. 2002, 83, 3075-3784. [CrossRef]

18. Koren, S.; Walenz, B.P.; Berlin, K.; Miller, J.R.; Bergman, N.H.; Phillippy, A.M. Canu:scalable and accurate long-read assembly via adaptive k-mer weighting and repeat separation. Genome Res. 2017, 27, 722-736. [CrossRef]

19. Altschul, S.F.; Gish, W.; Miller, W.; Myers, E.W.; Lipman, D.J. Basic local alignment search tool. J. Mol. Biol. 1990, 215, 403-410. [CrossRef]

20. Li, H.; Durbin, R. Fast and accurate short read alignment with Burrows-Wheeler Transform. Bioinformatics 2009, 25, 1754-1760. [CrossRef]

21. Drummond, A.J.; Rambaut, A. BEAST: Bayesian evolutionary analysis by sampling trees. BMC Evol. Biol. 2007, 7, 214. [CrossRef]

22. Haider, N.; Laaksonen, S.; Kjær, L.J.; Oksanen, A.; Bødker, R. The annual, temporal and spatial pattern of Setaria tundra outbreaks in Finnish reindeer: A mechanistic transmission model approach. Parasit Vectors 2018, 11, 565. [CrossRef] [PubMed]

23. Haider, N.; Cuellar, A.C.; Kjær, L.J.; Sørensen, J.H.; Bødker, R. Microclimatic temperatures at Danish cattle farms, 2000-2016: Quantifying the temporal and spatial variation in the transmission potential of Schmallenberg virus. Parasit Vectors 2018, 11, 128. [CrossRef] [PubMed]

24. Fritz, M.; Taty Taty, R.; Portella, C.; Guimbi, C.; Mankou, M.; Leroy, E.M.; Becquart, P. Re-emergence of chikungunya in the Republic of the Congo in 2019 associated with a possible vector-host switch. Int. J. Infect. Dis. 2019, 84, 99-101. [CrossRef] [PubMed]

25. Takaya, S.; Kutsuna, S.; Nakayama, E.; Taniguchi, S.; Tajima, S.; Katanami, Y.; Yamamoto, K.; Takeshita, N.; Hayakawa, K.; Kato, Y.; et al. Chikungunya Fever in Traveler from Angola to Japan, 2016. Emerg. Infect. Dis. 2017, 23, 156-158. [CrossRef] [PubMed]

26. ISchuffenecker, S.; Iteman, I.; Michault, A.; Murri, S.; Frangeul, L.; Vaney, M.; Lavenir, R.; Pardigon, N.; Reynes, J.; Pettinelli, F.; et al. Genome microevolution of chikungunya viruses causing the Indian Ocean outbreak. PLoS Med. 2006, 3, e263.

27. Tsetsarkin, K.A.; McGee, C.E.; Volk, S.M.; Vanlandingham, D.L.; Weaver, S.C.; Higgs, S. Epistatic roles of E2 glycoprotein mutations in adaption of chikungunya virus to Aedes albopictus and Ae. aegypti mosquitoes. PLOS ONE 2009, 4, e6835.

28. Agarwal, A.; Sharma, A.K.; Sukumaran, D.; Parida, M.; Dash, P.K. Two novel epistatic mutations (E1:K211E and E2:V264A) in structural proteins of Chikungunya virus enhance fitness in Aedes aegypti. Virology 2016, 497, 59-68. [CrossRef] 
29. Kamgang, B.; Wilson-Bahun, T.A.; Irving, H.; Kusimo, M.O.; Lenga, A.; Wondji, C.S. Geographical distribution of Aedes aegypti and Aedes albopictus (Diptera: Culicidae) and genetic diversity of invading population of Ae. albopictus in the Republic of the Congo. Version 3. Wellcome Open Res. 2018, 3, 79. [CrossRef]

30. Althouse, B.M.; Guerbois, M.; Cummings, D.A.T.; Diop, O.M.; Faye, O.; Faye, A.; Diallo, D.; Sadio, B.D.; Sow, A.; Faye, O.; et al. Role of monkeys in the sylvatic cycle of chikungunya virus in Senegal. Nat. Commun. 2018, 9, 1046. [CrossRef]

31. Makiala-Mandanda, S.; Ahuka-Mundeke, S.; Abbate, J.L.; Pukuta-Simbu, E.; Nsio-Mbeta, J.; Berthet, N.; Leroy, E.M.; Becquart, P.; Muyembe-Tamfum, J. Identification of Dengue and Chikungunya Cases Among Suspected Cases of Yellow Fever in the Democratic Republic of the Congo. Vector Borne Zoonotic Dis. 2018, 18, 364-370. [CrossRef] [PubMed]

(C) 2020 by the authors. Licensee MDPI, Basel, Switzerland. This article is an open access article distributed under the terms and conditions of the Creative Commons Attribution (CC BY) license (http://creativecommons.org/licenses/by/4.0/). 